\title{
Monitoring forests in space and time using close-range sensing
}

\author{
Vastaranta, M. ${ }^{1 *}$, Saarinen, N. ${ }^{1,2}$, Yrttimaa, T. ${ }^{1}$, Kankare, V. ${ }^{1}$, Junttila, S. ${ }^{1,2}$ \\ ${ }^{1}$ School of Forest Sciences, University of Eastern Finland, Yliopistokatu 7, P.O.Box 111, FI-80101 \\ Joensuu, Finland; mikko.vastaranta@uef.fi, tuomas.yrttimaa@uef.fi, ville.kankare@uef.fi \\ ${ }^{2}$ Department of Forest Sciences, University of Helsinki, P.O. Box 27, 00014 University of Helsinki, \\ Finland; ninni.saarinen@helsinki.fi, samuli.junttila@helsinki.fi \\ *Author to whom correspondence should be addressed.
}

\begin{abstract}
In this review, we summarize the current state-of-the-art in the utilization of close-range sensing in forest monitoring. We include technologies, such as terrestrial and mobile laser scanning as well as unmanned aerial vehicles, which are mainly used for collecting detailed information from single trees, forest patches or small forested landscapes. Based on the current published scientific literature, the capacity to characterize changes in forest ecosystems using close-range sensing has clearly been recognized. Forest growth has been the most investigated cause for changes and terrestrial laser scanner the most applied sensor for capturing forest structural changes. Unmanned aerial vehicles, on the other hand, have been used to acquire aerial imagery for detecting tree height growth and monitoring forest health. Mobile laser scanning has not yet been used in forest change monitoring except for a few early investigations. Considering the length of the forest growth process, investigated time spans have been rather short, less than 10 years. In addition, data from only two time points have been used in many of the studies, which has further been limiting the capability of understanding dynamics related to forest growth. In general, method development and quantification of changes have been the main interests so far regardless of the driver of change. This shows that the close-range remote sensing community has just started to explore the time dimension and its possibilities for forest characterization.
\end{abstract}

Keywords: forest change, remote sensing, natural phenomena, growth, tree health, forest operations

\section{Context}

Forests change over time and across space due to natural phenomena and anthropogenic processes. Biotic changes, such as forest growth and damage, affect forest structure. The whole forest growth process from a seedling to the regeneration stage may take more than 50 years in economically managed forests and more than one hundred years in natural forests (e.g., 200 years in boreal forest conditions). Forest growth process can be characterized as cyclic because growth rates vary within and between growing seasons (Dempewolf et al. 2017). Tree stem and branches grow annually in width and height. Conifer trees are typically evergreen, but leaves of deciduous trees emerge in the spring and fall in the autumn. Forest growth process is also linked to the decomposition process 
which affects the amount of dead wood (Yrttimaa et al. 2019). Natural phenomena, such as insect damage, the spread of pathogens, wind damage, and forest fires, shape forests at different spatial and temporal scales. Insect damage, that is often combined with the spread of pathogenic fungi, causes defoliation and changes in the bark whereas winds fell trees or tree parts (Saarinen et al. 2016) and fire burns low vegetation, needle mass and possibly also reshapes the structure of trees (Gupta et al. 2015, Carvajal-Ramírez et al. 2019). Wind damage is abrupt, forest fire may last for weeks, and insect damage is often spread widely in space and may last over several years (Vastaranta et al. 2012, Korovin 1996, Junttila et al. 2019). The temporal distribution of these damage events is usually unpredictable and the spatial scale varies from single trees to landscapes. There are also abiotic changes that affect the forest structure. These include land-use changes, silvicultural and harvesting operations. Considering the applicable area for close-range sensing, land-use changes are not included in this review. In managed forests, trees are often planted, seedlings are tended, and several thinning operations are carried out during the rotation period (Holopainen et al. 2014). Silvicultural practices vary a great deal, but in general, a proportion of trees is typically removed in silvicultural and harvesting operations (Liang et al. 2012). The spatial distribution of silvicultural events at the landscape-level can be characterized somewhat unpredictable as the temporal distribution is cyclic (White et al. 2018). At the level of a forest stand and a tree, changes caused by forest operations can be seen as abrupt changes that take place within a few days. Thus, spatiotemporal information is needed to improve the understanding of, or quantify, the consequences of these natural phenomena, processes, and human activities with varying temporal and spatial patterns and dimensions. Close-range sensing technologies, such as terrestrial laser scanning (TLS), mobile laser scanning (MLS) and the use of unmanned aerial vehicles (UAVs) are included in our review as they are mainly used for the collection of detailed information from single trees, forest patches or small forested landscapes.

\section{Tree and forest growth}

Srinivasan et al. (2014) used TLS data from two time points (2009 and 2012) for modeling tree biomass changes in East Texas. They reported that for changes in the above-ground biomass (AGB) of 29 loblolly pines (Pinus taeda L.), modeling the change in AGB with canopy volume and height change metrics provided the best results. Kaasalainen et al. (2014) collected a timeseries of TLS data from one Norway maple (Acer platanoides L.) growing in a city with five observation points during a 4-year time period. They built the tree model using Quantitative Structure Modelling (QSM, Raumonen et al. 2013) to detect changes in tree branch volume and branch length, caused by growth and mortality. Sheppard et al. (2017) used QSMs to investigate annual growth of 21 wild cherry (Prunus avium L.) trees in terms of diameter and height, stem and branch volume, as well as the fraction of merchantable timber. They collected TLS data over a 3year time period so that three QSMs per tree were constructed. Sheppard et al. (2017) as well as Kaasalainen et al. (2014) earlier, were able to detect and quantify the growth of individual branches as well as identify volume reductions due to pruning. However, although these first studies were promising, later studies have shown that due to occlusion it is almost impossible to detect all the 
branches in field conditions from TLS data (e.g. Pyörälä et al. 2018) and that may limit the applicability of certain applications.

For the forest growth analyses, it is not necessary to reconstruct the whole tree structure. For example, Hess et al. (2018) used bi-temporal TLS data to develop a voxel-based method for analyzing changes in canopy occupancy through time. Their method can be used at the local neighborhood level for revealing the extent of canopy space filling, identifying interactions between trees, and analysis of complementary space use. Kunz et al. (2019) used TLS data to capture the three-dimensional structure of trees and investigated their temporal dynamics. Bitemporal TLS data was collected between 2012 and 2016 and QSMs were then used to reconstruct the tree stem and the branches followed by the generation of 2D and 3D alpha-shapes for deriving additional crown shape and size parameters. With a TLS-based method, they were able to investigate crown complementarity, crown plasticity, and wood volume allocation. Respectively, Luoma et al. (2019) used bi-temporal TLS data (2008 and 2017) to investigate changes in stem forms. Of the investigated 35 trees, which were mainly conifers, changes in stem taper, cylindrical form factor, form quotient, and stem slenderness were analyzed. The changes in the stem taper varied from $-34 \%$ to $9 \%$, the cylindrical form factor from $1 \%$ to $18 \%$, the form quotient from $4 \%$ to $35 \%$, and the stem slenderness from $-2 \%$ to $6 \%$. Tree branches have circadian movements that can be revealed and investigated using a time series of TLS data (Puttonen et al. 2016). To reveal the phenomena, they measured two Silver birches (Betula pendula Roth), and each tree was recorded by 14 (Finland) and 77 (Austria) individual laser scans between sunset and sunrise. The resulting point clouds were used in creating a time series of branch movements. The vertical movements of the birch crowns varied between -10.0 and $5.0 \mathrm{~cm}$ at sunrise compared to the situation at sunset at the Finnish study site. Respectively, the maximum detected representative point movement was $10.0 \mathrm{~cm}$ in the Austrian data.

UAV imagery has been used to derive tree growth (Guerra-Hernandez et al. 2017, Dempewolf et al. 2017). In both studies, point clouds were generated from images using structure from motion and individual trees were recognized from this data. Guerra-Hernandez et al. (2017) used data from 2015 and 2017 to derive biomass change based on the changes in tree height and crown area. Dempewolf et al. (2017) aimed for characterizing intra-seasonal tree height growth and had four observation points in time during a single growing season. Their test site was a 2-hectare temperate mixed forest stand of varying age and successional stage in central Europe. Their results showed median growth rates of $68 \mathrm{~cm}$ between 27 May and 19 August for Norway spruce (Picea abies (L.) H. Karst), $93 \mathrm{~cm}$ for Scots pine (Pinus sylvestris L.), $106 \mathrm{~cm}$ for Silver birch, and $26 \mathrm{~cm}$ for European beech (Fagus sylvatica L.). These height growth results agreed well with published field observations for these species. They were also able to derive intra-annual tree height growth for groups of trees within a forest, although the UAV imagery-based height growth measurements for individual trees showed high variability. 


\section{Tree phenology and health}

$\mathrm{Bi}$ - and multi-temporal TLS data have been used for detecting leaf flush and autumn senescence. Calders et al. (2015) used TLS time series from four scan locations during 48 measurement days in a deciduous forest in the Netherlands to monitor spring phenology in 2014. They derived gap probabilities and vertical plant profiles from the TLS point clouds, and calculated plant area index (PAI) as a total canopy integrated PAI and as values at different horizontal layers. Xi et al. (2019) used a compact and low-cost 3D fusion scanning system with a multi-segment Leddar (light emitting diode detection and ranging, LeddarTech, Quebec City, Quebec, Canada), a monocular camera, and rotational robotics to recover hemispherical, colored point clouds. The system was applied to scan a poplar (Populus spp.) stand four times during autumnal leaf drop $\left(9^{\text {th }}\right.$ September - $17^{\text {th }}$ October 2018). A vertical volume profile of the canopy was derived using a voxel-based approach as gap fraction and path distribution were used to derive PAI. Leaf-area index values were estimated by contrasting leaf-on and leaf-off gap fraction values.

Time-series of UAV imagery have been used to monitor forest health. Kloucek et al. (2019) used UAV mounted RGB (Red, Green, Blue) and CIR (Color-infrared) cameras for the detection of bark beetle infestation. They acquired imagery four times between June and October in 2017. Four composite RGB/CIR orthomosaics and point clouds were created. Treetops were automatically detected using canopy height models and then visually inspected in the orthomosaic to validate the detection. Each treetop was then visually classified according to its health status (i.e., dead, healthy, or infested) for each time point, and dead trees were excluded from the analyses. From the processed orthomosaics, selected vegetation indices were calculated and used to distinguish healthy trees from the infested ones throughout the observation period. They discovered differences in the spectral responses, especially in greenness index, early after the bark beetle outbreak. Dash et al. (2017) assessed very high resolution UAV imagery for the monitoring of forest health during a simulated disease outbreak. They simulated a disease outbreak in mature Monterey pines (Pinus radiata D. Don) located within a 7.3 ha stand using a targeted application of herbicide. Methods for monitoring physiological stress were developed using multi-spectral imagery that was acquired nine times during 125 days (Oct 2015-March 2016). Based on the experiment, physiological stress could be detected from the red edge and the near infrared bands approximately 30 days after the herbicide treatment.

\section{Natural disturbances and harvesting operations}

Liang et al. (2012) detected harvested trees over five plots based on bi-temporal TLS data that were collected before and after harvesting in 2008. They used change detection that was based on a comparison of bi-temporal voxel elements. Almost all of the removed trees could be automatically located with this method. Saarinen et al. (2013) used MLS data from 2009, 2010, 2011 and 2012 to monitor vegetation changes, which included natural growth and damage due to erosion, in a riparian environment. They classified the vegetation based on height and density metrics for each year using a $2 \mathrm{~m}$ spatial resolution. The differences between vegetation layers were calculated to reveal the annual changes. For developing methods for quantifying impacts of 
fire in a forested landscape, Gupta et al. (2015) used bi-temporal TLS data and prescribed burn. Eighteen descriptive metrics characterizing changes in vegetation cover, volume and height were derived from the bi-temporal TLS point clouds and used to analyze and visualize changes in a control and a fire-altered plot. The change metrics were found to be rather stable in the unaltered natural landscape, whilst being sensitive enough to detect fire-induced changes in the understory. UAVs have also been used to monitor forest fires. Carvajal-Raminez et al. (2019) investigated fire severity classification based on pre- and post-fire multispectral imagery in a controlled experiment. The study site covered 12 ha of Mediterranean forests. The UAV was equipped with a highresolution multispectral camera including green, red, near-infrared, and red-edge bands. They investigated the temporal differences (d) between pre- and post-fire values of the Excess Green Index (EGI), Normalized Difference Vegetation Index (NDVI), and Normalized Difference Red Edge (NDRE) index, and concluded that dNDVI was the index that best estimated the fire severity.

\section{Conclusions}

The capacity of close-range sensing to characterize changes in forest ecosystems has been clearly recognized. Forest growth was the most investigated topic in the reviewed literature, whereas TLS was mainly used for characterizing changes. Imagery acquired with UAVs was used to detect tree height growth and to monitor forest health. MLS has not yet been used for forest change monitoring. The time periods in the reviewed studies were rather short $(<10$-years) considering the length of ecological succession. In addition, true time series (i.e., data from more than two time points) of TLS, MLS, and UAVs are still mainly lacking, limiting the understanding of forest growth as a phenomenon. In general, development of methods as well as identifying and quantifying changes were the main interest of the reviewed studies regardless of the driver of change. This implies that there is space for exploring the time dimension and the possibilities it can provide for characterizing forests.

\section{Author Contributions}

All authors have read and agreed to the published version of the manuscript. Writing-original draft preparation, M.V.; writing — review and editing, all the authors.

\section{Conflicts of Interest}

The authors declare no conflict of interest.

\section{References}

Calders, K., Schenkels, T., Bartholomeus, H., Armston, J., Verbesselt, J. and Herold, M., 2015. Monitoring spring phenology with high temporal resolution terrestrial LiDAR measurements. Agricultural and forest meteorology, 203, pp.158-168.

Carvajal-Ramírez, F., Marques da Silva, J.R., Agüera-Vega, F., Martínez-Carricondo, P., Serrano, J. and Moral, F.J., 2019. Evaluation of Fire Severity Indices Based on Pre-and Post-Fire Multispectral Imagery Sensed from UAV. Remote Sensing, 11(9), p.993. 
Dash, J.P., Watt, M.S., Pearse, G.D., Heaphy, M. and Dungey, H.S., 2017. Assessing very high resolution UAV imagery for monitoring forest health during a simulated disease outbreak. ISPRS Journal of Photogrammetry and Remote Sensing, 131, pp.1-14.

Dempewolf, J., Nagol, J., Hein, S., Thiel, C. and Zimmermann, R., 2017. Measurement of withinseason tree height growth in a mixed forest stand using UAV imagery. Forests, 8(7), p.231.

Guerra-Hernández, J., González-Ferreiro, E., Monleón, V., Faias, S., Tomé, M. and Díaz-Varela, R., 2017. Use of multi-temporal UAV-derived imagery for estimating individual tree growth in Pinus pinea stands. Forests, 8(8), p.300.

Gupta, V., Reinke, K., Jones, S., Wallace, L. and Holden, L., 2015. Assessing metrics for estimating fire induced change in the forest understorey structure using terrestrial laser scanning. Remote Sensing, 7(6), pp.8180-8201.

Hess, C., Härdtle, W., Kunz, M., Fichtner, A. and von Oheimb, G., 2018. A high-resolution approach for the spatiotemporal analysis of forest canopy space using terrestrial laser scanning data. Ecology and evolution, 8(13), pp.6800-6811.

Holopainen, M., Vastaranta, M. and Hyyppä, J., 2014. Outlook for the next generation's precision forestry in Finland. Forests, 5(7), pp.1682-1694.

Junttila, S., Holopainen, M., Vastaranta, M., Lyytikäinen-Saarenmaa, P., Kaartinen, H., Hyyppä, J. and Hyyppä, H., 2019. The potential of dual-wavelength terrestrial lidar in early detection of Ips typographus (L.) infestation-Leaf water content as a proxy. Remote Sensing of Environment, 231, p.111264.

Kaasalainen, S., Krooks, A., Liski, J., Raumonen, P., Kaartinen, H., Kaasalainen, M., Puttonen, E., Anttila, K. and Mäkipää, R., 2014. Change detection of tree biomass with terrestrial laser scanning and quantitative structure modelling. Remote Sensing, 6(5), pp.3906-3922.

Korovin, G.N., 1996. Analysis of the distribution of forest fires in Russia. In Fire in ecosystems of boreal Eurasia (pp. 112-128). Springer, Dordrecht.

Klouček, T., Komárek, J., Surový, P., Hrach, K., Janata, P. and Vašíček, B., 2019. The Use of UAV Mounted Sensors for Precise Detection of Bark Beetle Infestation. Remote Sensing, 11(13), p.1561.

Kunz, M., Fichtner, A., Härdtle, W., Raumonen, P., Bruelheide, H. and von Oheimb, G., 2019. Neighbour species richness and local structural variability modulate aboveground allocation patterns and crown morphology of individual trees. Ecology Letters.

Liang, X., Hyyppä, J., Kaartinen, H., Holopainen, M. and Melkas, T., 2012. Detecting changes in forest structure over time with bi-temporal terrestrial laser scanning data. ISPRS International Journal of Geo-Information, 1(3), pp.242-255.

Luoma, V., Saarinen, N., Kankare, V., Tanhuanpää, T., Kaartinen, H., Kukko, A., Holopainen, M., Hyyppä, J. and Vastaranta, M., 2019. Examining Changes in Stem Taper and Volume Growth with Two-Date 3D Point Clouds. Forests, 10(5), p.382. 
Puttonen, E., Briese, C., Mandlburger, G., Wieser, M., Pfenningbauer, M., Zlinszky, A. and Pfeifer, N. 2016. Quantification of overnight movement of birch (Betula pendula) branches and foliage with short interval terrestrial laser scanning. Frontiers in Plant Science 7, p. 222.

Raumonen, P., Kaasalainen, M., Åkerblom, M., Kaasalainen, S., Kaartinen, H., Vastaranta, M., Holopainen, M., Disney, M. and Lewis, P., 2013. Fast automatic precision tree models from terrestrial laser scanner data. Remote Sensing, 5(2), pp.491-520.

Saarinen, N., Vastaranta, M., Vaaja, M., Lotsari, E., Jaakkola, A., Kukko, A., Kaartinen, H., Holopainen, M., Hyyppä, H. and Alho, P., 2013. Area-based approach for mapping and monitoring riverine vegetation using mobile laser scanning. Remote Sensing, 5(10), pp.5285-5303.

Saarinen, N., Vastaranta, M., Honkavaara, E., Wulder, M.A., White, J.C., Litkey, P., Holopainen, M. and Hyyppä, J., 2016. Using multi-source data to map and model the predisposition of forests to wind disturbance. Scandinavian journal of forest research, 31(1), pp.66-79.

Sheppard, J., Morhart, C., Hackenberg, J. and Spiecker, H., 2016. Terrestrial laser scanning as a tool for assessing tree growth. iForest-Biogeosciences and Forestry, 10(1), p.172.

Srinivasan, S., Popescu, S.C., Eriksson, M., Sheridan, R.D. and Ku, N.W., 2014. Multi-temporal terrestrial laser scanning for modeling tree biomass change. Forest Ecology and Management, 318 , pp.304-317.

Vastaranta, M., Korpela, I., Uotila, A., Hovi, A. and Holopainen, M., 2012. Mapping of snowdamaged trees based on bitemporal airborne LiDAR data. European journal of forest research, 131(4), pp.1217-1228.

White, J.C., Saarinen, N., Kankare, V., Wulder, M.A., Hermosilla, T., Coops, N.C., Pickell, P.D., Holopainen, M., Hyyppä, J. and Vastaranta, M., 2018. Confirmation of post-harvest spectral recovery from Landsat time series using measures of forest cover and height derived from airborne laser scanning data. Remote sensing of environment, 216, pp.262-275.

Yrttimaa, T., Saarinen, N., Luoma, V., Tanhuanpää, T., Kankare, V., Liang, X., Hyyppä, J., Holopainen, M. and Vastaranta, M., 2019. Detecting and characterizing downed dead wood using terrestrial laser scanning. ISPRS journal of photogrammetry and remote sensing, 151, pp.76-90.

Xi, Z., Hopkinson, C., Rood, S.B., Barnes, C., Xu, F., Pearce, D. and Jones, E., 2019. A Lightweight Leddar Optical Fusion Scanning System (FSS) for Canopy Foliage Monitoring. Sensors, 19(18), p.3943. 